\title{
Inpatient occupational therapists hand-splinting practice for clients with stroke: A cross-sectional survey from Ireland
}

\author{
Cormican Adrienne, Chockalingam Manigandan \\ Occupational Therapy Discipline, School of Health Sciences, National University of Ireland, Galway, Ireland
}

\begin{abstract}
Introduction: Hand splinting after stroke is a common practice despite inadequate evidence. This warrants a better understanding of the therapists' splinting practice, to develop clinically meaningful treatment options. Aims: The study examined the nature and prevalence of the factors associated with therapists' hand splinting practice and their perceived splinting efficacy. Settings and Design: A cross-sectional national survey of hand-splinting practice among inpatient occupational therapists (OTs) in Ireland. Materials and Methods: Sixty-two therapists participated in this national survey.Statistical analysis used: A number of factors were analyzed to explore their relationship with therapists' perception of splint efficacy using Spearman's rank order correlation. Results: $53(85.5 \%)$ out of 62 survey respondents prescribed splints to their clients at the time of taking the survey. To reduce spasticity, to correct contractures and thus increase range of motion (ROM) were the commonly used splinting goals. These were the goals that were significantly associated with the therapists' splinting efficacy too. Conclusions: Hand-splint prescription following stroke was found to be a common practice among OTs who perceive splints to be quite effective. A custom-made, volar forearmbased wrist-hand splint is the preferred splint among therapists to achieve a number of clinical aims such as improving ROM, stretching soft tissue contractures and reducing spasticity in the upper extremity. A wide variety of splinting regimens is currently practiced, reflecting the lack of a universally accepted and comprehensive practice guideline to regulate therapy. Methodologically valid clinical trials evaluating the efficacy of therapist-preferred splints in achieving their favored outcomes are needed. Development of common, universally accepted therapeutic guidelines based on comprehensive scientific review of such studies is thus needed.
\end{abstract}

Key words: Hand splint, occupational therapy, rehabilitation, stroke, survey

\section{Introduction}

Stroke is the most prevalent disabling neurological disease in the developed world. ${ }^{[1]}$ It is the most common cause of acquired major disability in Ireland..$^{[2]}$ Upper limb (UL) disabilities adversely affect the quality of life for stroke survivors, despite intense therapeutic efforts. ${ }^{[3]}$ UL hemiplegia, spasticity and contractures are common complications experienced by clients post-stroke and are very disabling. ${ }^{[3,4]}$ Spasticity and contractures restrict joint range of motion (ROM), limit function, cause pain, and

\begin{tabular}{|l|l|}
\hline \multicolumn{2}{|c|}{ Access this article online } \\
\hline Quick Response Code: & Website: \\
\hline & www.ruralneuropractice.com \\
\cline { 2 - 3 } & \\
\hline
\end{tabular}

interfere with the performance of everyday activities. ${ }^{[5]}$ To address these effects in rehabilitation, splints are commonly used. The clinical aims of splinting include reducing muscle spasticity, managing pain, improving ROM, preventing and/or reducing contractures, assisting with hygiene, enhancing functional activities or independence in activities of daily living, preventing overstretching and edema. $^{[4,6-8]}$

However, splinting for post-stroke spasticity and contractures is contentious and debate continues unabated due to insufficient evidence unambiguously documenting its effectiveness. ${ }^{[9,10]}$ Recent literature has determined splinting to be effective in some clinical situations [5,9-13] $^{[3}$ (example, shorter daily splinting time, use of dynamic lycra splint), but ineffective in others. ${ }^{[6,14,15]}$ However, most of these studies have been critiqued for their methodological limitations, which has undermined their findings somewhat. ${ }^{[16]}$ Some of the commonly documented

\section{Address for correspondence:}

Mr. Manigandan Chockalingam, Occupational Therapy Discipline, Moyola Building, National University of Ireland, Galway, Ireland.

E-mail: manigandan93@yahoo.com 
concerns with these studies include inadequate emphasis on various potential confounders such as objective measure of splinting adherence, lack of rationalization for the time of initiation of splinting treatment, splint wearing schedule and/or type/position of splint used. ${ }^{[17,18]}$ Thus the results from the literature are inconclusive and inconsistent, leading to controversy over splinting practice following stroke. Consequently, in the absence of more scientifically validated evaluations, much is left to subjective clinical judgement, resulting in varying splinting practices. This may increase the likelihood of errors in clinical reasoning and/or the risk of therapists following routine procedures (potentially in inappropriate situations). ${ }^{[19]}$

An inadequate evidence-base, coupled with the widespread use of splint therapy, not only warrants an increased urgency to assess splinting efficacy, but also necessitates a better understanding of the therapists' current splinting practice, to draw up clinically meaningful treatment options. While the splinting efficacy has been addressed generally in the literature, the therapists' current splinting practice has received inadequate attention. To the best of the researchers' knowledge, there is only one study ${ }^{[8]}$ that addresses the issue of hand splinting practices following stroke. This study's findings indicate a conflicting splinting practice that ranged from 'not splinting at all' to 'always splinting'. In the three decades following this study, a lot has been changed in stroke rehabilitation practices, ${ }^{[20-25]}$ yet the paucity in literature addressing therapists' splinting practice still remains unchanged. This dearth in literature necessitates further exploration which is fundamental for engaging therapists in objective and scientifically validated reasoning. ${ }^{[19]}$ Thus, this study aimed at exploring Irish occupational therapists' perceived splint efficacy and their splint prescription pattern in stroke.

\section{Materials and Methods}

\section{Procedure}

The study was a cross-sectional survey of inpatient occupational therapists (OTs) in Ireland. A list of all public hospitals under the Irish Health Service Executive (HSE) and other teaching and/or rehabilitation hospitals associated with the HSE was identified for the study. OTs working in these settings were invited by the principal investigator to participate in the study, excluding community OTs, private OTs, private hospital OTs and those on long leave. A final list of one hundred and thirty OTs was identified. A questionnaire pack including an invitation letter, a participant's information sheet and a reply-paid, return-addressed envelope was posted out to all eligible participants. Questionnaires were returned within the study period of three weeks with a reminder sent after two weeks. The returned, anonymous questionnaires were serially numbered and stored safely to maintain participants' anonymity. An implied consent for participation was thus obtained. ${ }^{[26]}$

\section{Instruments}

A researcher-designed questionnaire to study the therapists' splint prescription pattern and perception of splint efficacy was used in the study, which has a sixpoint Likert scale. Development of such a questionnaire was required owing to limited literature on this research topic. To allow for a more comprehensive and qualitative understanding of the therapists' views, open ended questions were also included. In an attempt to ensure construct validity, ${ }^{[27]}$ theoretical concepts from an extensive literature review on splinting in stroke were used in the development of the questionnaire. The layout of the questionnaire was kept simple. A 'funnel approach' of progressively narrowing scope was also used in its development. ${ }^{[28]}$ In an attempt to ensure content validity and face validity, the questionnaire was piloted with eight experienced OTs who critiqued both the language and the content of the instrument. All of their comments were incorporated into the 23-itemed final questionnaire, which was used in the survey. Given the limited scope of the study, a detailed evaluation of the questionnaire's validity or reliability was not possible.

\section{Results}

Sixty-two (response rate of 47.7\%) completed questionnaires were returned. Table 1 shows the distribution of the study participants. The majority $41(66.1 \%)$ have an undergraduate degree and 42(67.7\%) work as senior OTs.

Table 2 shows the therapists' splinting knowledge and their splint prescription patterns. Most of them reported that their splinting knowledge is primarily from their university education 51(82.3\%) and from peer learning $51(82.3 \%)$. A considerable number of participants have also attended additional splinting programs for further skill development $44(71 \%)$. The majority of the respondents 53(85.5\%) stated that they prescribe splints to their clients and felt competent in prescribing and/ or fabricating them. Content analysis of the $9(14.5 \%)$ participants' responses, who did not prescribe hand splints, revealed rationales for their non-prescription, specifically: insufficient scientific evidence for splinting, lack of splinting experience, and preference of functional use of hand over hand splinting. More than a third of the therapists $22(35.5 \%)$ reported that they prescribe 
Table 1: Descriptive characteristics of occupational therapists participated in the study

\begin{tabular}{lc}
\hline Category & $\boldsymbol{n}(\%)$ \\
\hline Level of education & $5(8.1)$ \\
Diploma in OT & $41(66.1)$ \\
Degree in OT & $6(9.7)$ \\
Masters (entry level to OT) & $8(12.9)$ \\
Masters & $1(1.6)$ \\
Postgraduate certificate & $1(1.6)$ \\
Doctorate & \\
Current position held & $13(21)$ \\
Staff grade OT & $42(67.7)$ \\
Senior OT & $3(4.8)$ \\
Clinical specialist OT & $4(6.5)$ \\
Head/manager OT & \\
Current work settings & $31(50)$ \\
Acute hospital & $23(37.1)$ \\
Rehabilitation hospital & $8(12.9)$ \\
Other & \\
Primary clinical population treated & $5(8.1)$ \\
Children & $12(19.4)$ \\
Adults & $28(45.1)$ \\
Older adults & $17(27.4)$ \\
Adults and older adults & $6.96(5.9)$ \\
Years of clinical experience in stroke rehabilitation & Mean (SD) \\
\hline OT: Occupational therapists &
\end{tabular}

OT: Occupational therapists

Table 2: Occupational therapists' splinting knowledge and prescription pattern

\begin{tabular}{lc}
\hline Factors & $\boldsymbol{n}(\%)$ \\
\hline OTs self-perceived level of competence in & \\
prescribing and fabricating splints & \\
Very competent & $9(14.8)$ \\
Competent & $35(57.3)$ \\
Neutral & $12(19.7)$ \\
Incompetent & $3(4.9)$ \\
Very incompetent & $2(3.3)$ \\
Source of splint fabrication knowledge & \\
University education & $51(82.3)$ \\
Trial and error approach & $25(40.3)$ \\
Joint sessions with colleagues' & $51(82.3)$ \\
Attending splinting courses & $44(71)$ \\
Other & $2(3.2)$ \\
Use of guidelines (national or in-house) for splint & \\
prescription & \\
Yes & $44(80)$ \\
No & $11(20)$ \\
Percentage of stroke clients receiving hand splints & \\
No splints & $9(14.52)$ \\
$<25 \%$ & $31(50)$ \\
$26-50 \%$ & $18(29.03)$ \\
$51-75 \%$ & $3(4.84)$ \\
$76-100 \%$ & $1(1.61)$ \\
\hline
\end{tabular}

splints to more than $25 \%$ of their post-stroke clients. A number of splinting guideline sources were reported by 44 participants in regulating their splint practice following stroke. Hospital departmental guidelines were the most commonly followed $(n=18,41 \%)$, while general positioning guidelines, national stroke guidelines, splint manufacturers' guidelines and national hand therapy guidelines were some of the other guidelines that were reported to be used.

Occupational therapists' choices of splints and their rationales for prescription

Table 3 shows the occupational therapists' choice of splints and their characteristics while prescribing splints to clients with stroke. Due to the small number of participants in the study, the 6-point Likert scale responses in the questionnaire were mathematically reduced to a 3-point Likert response ('Always' and 'very frequent' responses were reduced to 'often', 'occasionally' and 'rarely' responses were reduced to 'occasionally' and 'very rarely' and 'never' responses were reduced to 'never'), for all further statistical analyses. Most of the participants preferred static-splinting and preferred to customise splints for their clients. While a few OTs chose to correct their splints to accommodate clients' needs through serial static splinting, neither dynamic splinting nor static progressive splinting was preferred by the majority. Upon further exploration, lack of material resources, time and inadequate knowledge in fabricating dynamic splints were reported to be the main reasons for the infrequent use of dynamic hand splinting.

Therapists appear to be referring to volar forearm-based wrist-hand splints [Figure 1] as two different splints namely, resting-position splint (placing the wrist in neutral position and thumb in radial abduction) and functional-position splint (placing the wrist in upto $30^{\circ}$ of extension and thumb in opposition) both look to be

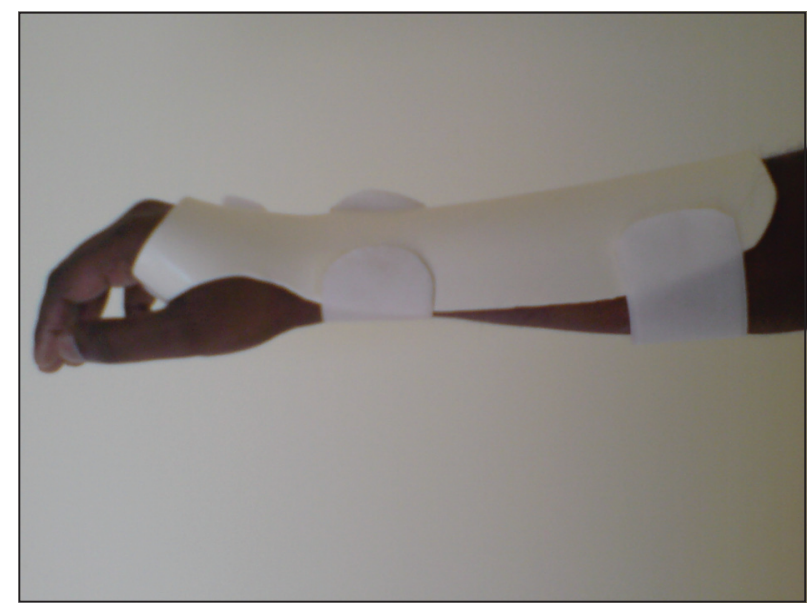

Figure 1: Custom-made volar forearm-based wrist-hand splint 
Table 3: Characteristics and choice of hand splints preferred by therapists

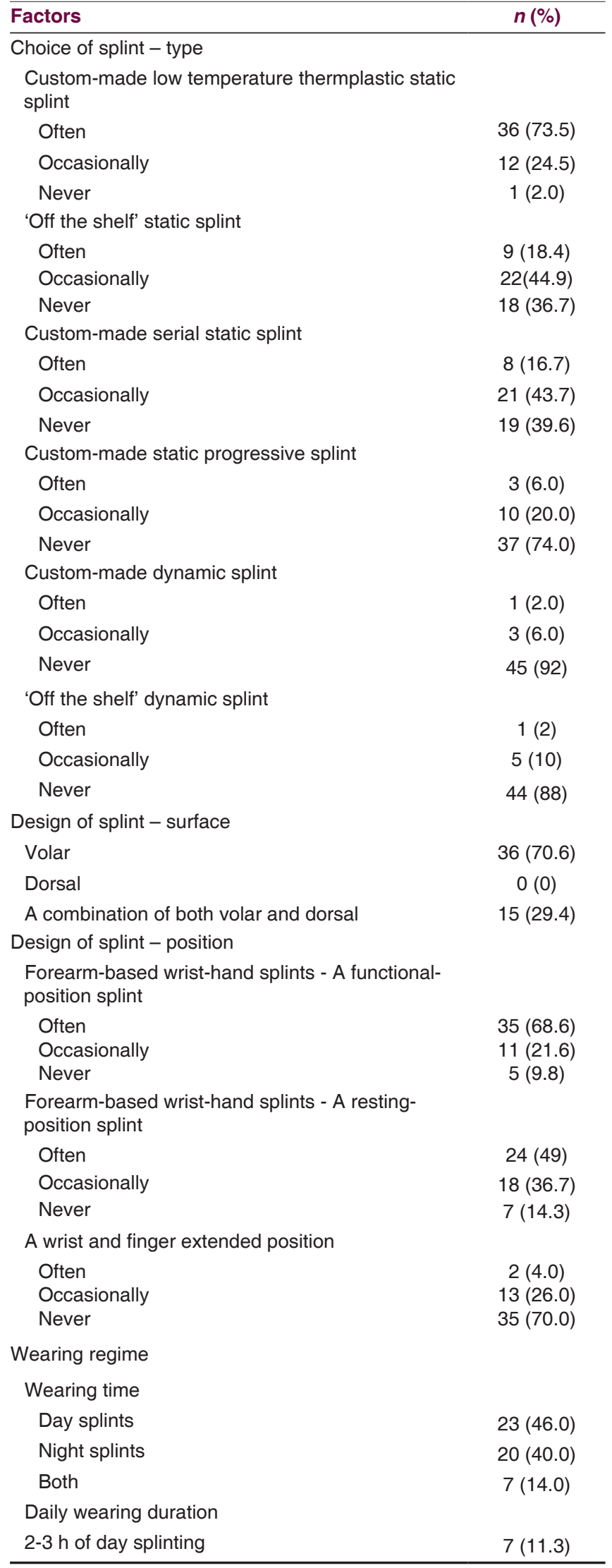

Table 3: (Contd..)

\begin{tabular}{lc}
\hline Factors & $\boldsymbol{n}(\%)$ \\
\hline Alternate 2-3 $\mathrm{h}$ on and off & $16(25.8)$ \\
3-5 h day splinting & $6(9.7)$ \\
Alternate 3-5 h on and off & $7(11.3)$ \\
Overnight (8-12 h) & $19(30.6)$ \\
Few hours during the day and overnight & $7(11.3)$ \\
\hline
\end{tabular}

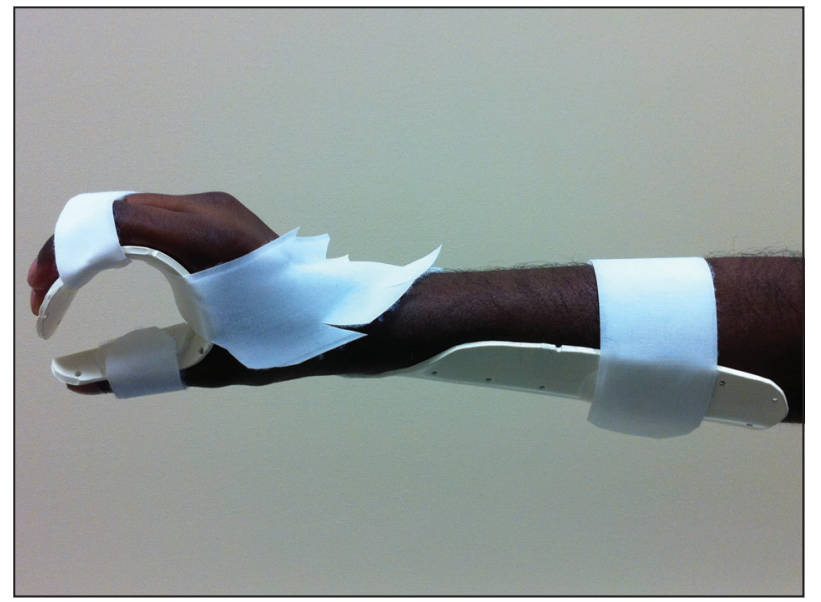

Figure 2: Custom-made dorsal forearm-based wrist splint

only minimally different from each other. The majority of the therapists $36(70.6 \%)$ preferred to prescribe volar forearm-based wrist-hand splints either alone or with dorsal forearm-based wrist splints [Figure 2] 15(29.4\%); however, none of them opted for dorsal forearm-based wrist splints exclusively. Reasons reported for the prescription of volar splints were easiness in applying, clients' reported comfort, enhanced clients' splinting adherence, therapists' observed clinical benefits through experience and their familiarity in fabrication.

Splinting the hand in volar forearm-based wristhand splints were the most preferred positions, while stretching the soft tissues by positioning the wrist and hand in as much extension as possible was the least preferred. With regard to splint wearing regimen, there is almost an equal preference for both day-splinting and night-splinting; however, there was a mixture of preferences among the therapists for the daily duration of splint use. Therapists believed that through daytime splinting, patients' splint adherence was better achieved due to enhanced comfort. Night splints were commonly prescribed to encourage functional movement of hand and to allow sensory input during the day.

A number of rationales were described by the participants for their splint prescription [Table 4]. Reducing muscle spasticity, preventing soft tissue contractures, maintaining joint alignment and increasing $\mathrm{ROM}$ are some of the most common reasons for splint prescription. Table 5 reports 
the therapists' perceived use of subjective and objective assessment methods during their splinting program. It is evident from this table that at least more than half of the participants were relying on subjective non-standardized assessments/observations for evaluating the usefulness of the splints (in terms of meeting their clinical aims) with an exception of pain management. Similarly almost half of the participants did not use any standardized assessment procedures for their evaluation.

\section{Occupational therapists' perceived splint efficacy among} post-stroke clients

Figure 3 shows the occupational therapists' perceptions

\begin{tabular}{|c|c|c|c|}
\hline Clinical aims of splinting & $\begin{array}{l}\text { Often } \\
n(\%)\end{array}$ & $\begin{array}{c}\text { Occasionally } \\
n(\%)\end{array}$ & $\begin{array}{l}\text { Never } \\
n(\%)\end{array}$ \\
\hline $\begin{array}{l}\text { To prevent soft tissue } \\
\text { contracture }\end{array}$ & $32(72.7)$ & $10(22.7)$ & $2(4.6)$ \\
\hline $\begin{array}{l}\text { To maintain muscle and } \\
\text { joint alignment }\end{array}$ & $26(59.1)$ & $17(38.6)$ & $1(2.3)$ \\
\hline $\begin{array}{l}\text { To reduce muscle } \\
\text { spasticity }\end{array}$ & $20(45.5)$ & $21(47.7)$ & $3(6.8)$ \\
\hline $\begin{array}{l}\text { To increase range of } \\
\text { movement }\end{array}$ & $20(45.6)$ & $16(36.4)$ & $8(18.2)$ \\
\hline $\begin{array}{l}\text { To correct existing } \\
\text { contracture }\end{array}$ & $17(38.6)$ & $14(31.8)$ & $13(29.6)$ \\
\hline To assist with hygiene & $16(36.4)$ & $21(47.7)$ & $7(15.9)$ \\
\hline $\begin{array}{l}\text { To manage wrist and } \\
\text { hand pain }\end{array}$ & $13(29.5)$ & $24(54.5)$ & $7(16)$ \\
\hline $\begin{array}{l}\text { To improve UL functional } \\
\text { movement }\end{array}$ & $12(27.3)$ & $22(50.0)$ & $10(22.7)$ \\
\hline $\begin{array}{l}\text { To enhance ADL } \\
\text { independence }\end{array}$ & $10(22.7)$ & $25(56.8)$ & $9(20.5)$ \\
\hline $\begin{array}{l}\text { To prevent overstretching } \\
\text { of soft tissue }\end{array}$ & $9(20.5)$ & $21(47.7)$ & $14(31.8)$ \\
\hline To reduce edema & $7(15.9)$ & $22(50.0)$ & $15(34.1)$ \\
\hline
\end{tabular}

about effectiveness of hand splinting among post-stroke clients. Almost two-thirds of the respondents 38(61.3\%) believe splinting to be effective or very effective; however more than a quarter of the participants $18(29 \%)$ are either undecided or unsure about their splint efficacy.

A number of factors were analyzed to explore their relationship with therapists' perception of splint efficacy using Spearman's rank order correlation. The following factors were found to be significant: influence of postgraduate education on therapists' perception $(P=0.343$, Sig. $=0.007)$, influence of undergraduate education on therapists' perception $(P=0.268$, Sig. $=0.044)$, the use of functional position splint $(P=0.290$, Sig. $=0.041)$ and the use of wrist and finger extension splint $(P=-0.282$, Sig. $=0.05)$. Reducing spasticity $(P=0.398$, Sig. $=0.008)$, correcting

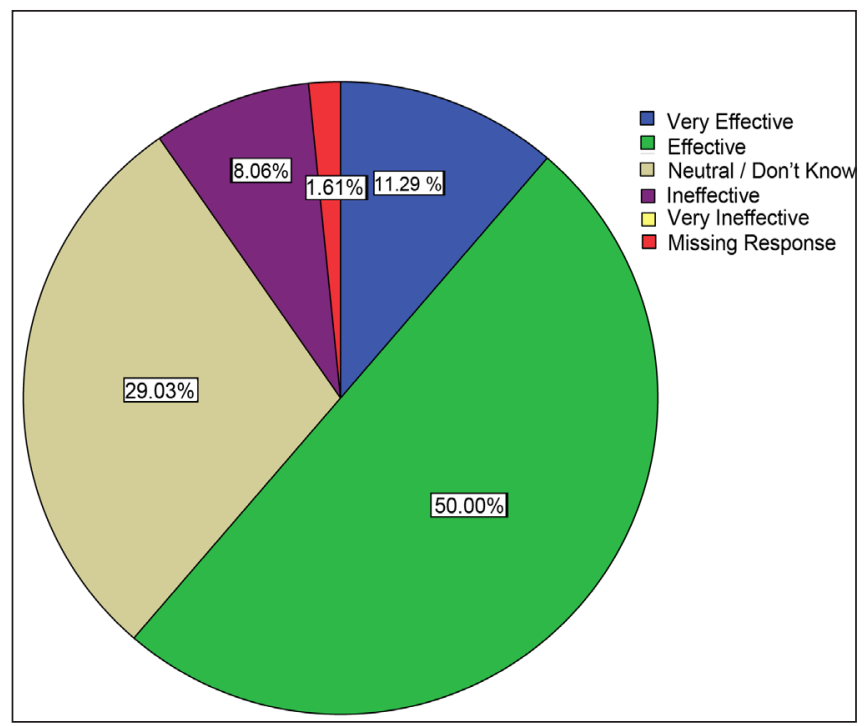

Figure 3: Occupational therapists' perceived splint efficacy among post-stroke clients

Table 5: Assessment methods used by occupational therapists during splinting

\begin{tabular}{|c|c|c|c|c|c|c|}
\hline \multirow[t]{2}{*}{ Rationale for splinting } & \multicolumn{3}{|c|}{$\begin{array}{l}\text { Use of non-standardized subjective } \\
\text { assessments }\end{array}$} & \multicolumn{3}{|c|}{$\begin{array}{c}\text { Use of standardized objective } \\
\text { assessments }\end{array}$} \\
\hline & $\begin{array}{l}\text { Often } \\
n(\%)\end{array}$ & $\begin{array}{c}\text { Occasionally } \\
n(\%)\end{array}$ & $\begin{array}{l}\text { Never } \\
n(\%)\end{array}$ & $\begin{array}{l}\text { Often } \\
n(\%)\end{array}$ & $\begin{array}{c}\text { Occasionally } \\
n(\%)\end{array}$ & $\begin{array}{l}\text { Never } \\
n(\%)\end{array}$ \\
\hline To reduce muscle spasticity & $23(74.2)$ & $5(16.1)$ & $3(09.7)$ & $5(16.7)$ & $11(36.7)$ & $14(46.7)$ \\
\hline To manage pain & $11(36.7)$ & $4(13.3)$ & $15(50.0)$ & $6(20.0)$ & $7(23.3)$ & $17(56.7)$ \\
\hline To prevent soft tissue contracture & $23(76.7)$ & $4(13.3)$ & $15(50.0)$ & $8(26.7)$ & $7(23.3)$ & $15(50.0)$ \\
\hline To correct existing contracture & $20(69.0)$ & $4(13.8)$ & $5(17.2)$ & $5(17.2)$ & $7(24.1)$ & $17(58.7)$ \\
\hline To assist with hygiene & $19(65.5)$ & $6(20.7)$ & $4(13.8)$ & $3(10.3)$ & $8(27.6)$ & $18(62.1)$ \\
\hline To increase range of movement & $18(62.1)$ & $7(24.1)$ & $4(13.8)$ & $8(27.6)$ & $6(20.7)$ & $15(51.7)$ \\
\hline To reduce edema & $17(58.6)$ & $6(20.7)$ & $6(20.7)$ & $3(10.3)$ & $8(27.6)$ & $18(62.1)$ \\
\hline To prevent soft tissue overstretching & $16(55.2)$ & $7(24.1)$ & $6(20.7)$ & $5(17.2)$ & $6(20.7)$ & $18(62.1)$ \\
\hline To improve UL functional movement & $17(58.6)$ & $8(27.6)$ & $4(13.8)$ & $6(20.7)$ & $10(34.5)$ & $13(44.8)$ \\
\hline To enhance ADL independence & $19(65.6)$ & $7(24.1)$ & $4(10.3)$ & $11(37.9)$ & $17(24.2)$ & $11(37.9)$ \\
\hline To maintain muscle and joint alignment & $21(72.41)$ & $7(24.14)$ & $1(3.45)$ & $7(24.14)$ & $9(31.03)$ & $13(44.8)$ \\
\hline
\end{tabular}


existing soft tissue contractures $(P=0.325$, Sig. $=0.033)$ and increasing $\operatorname{ROM}(P=0.370$, Sig. $=0.015)$ were identified as some of the splinting rationales which were also found to be significantly associated with their perceived splinting efficacy. However, none of the therapists' general characteristics (i.e. years of experience, level of education, current clinical position, type of current work settings and use of splinting guidelines) were significantly associated with their perceived splinting efficacy.

\section{Factors associated with splint prescription pattern among post-stroke clients}

Table 2 shows that 53(85.5\%) participants were actively prescribing splints to their clients. Being a senior OT (Cramer's V=0.420, Sig. $=0.001$ ), having university education as a source of splint fabrication knowledge (Cramer's V=0.449, Sig. $=0.002$ ) and following some form of splint prescription guidelines (Cramer's V=0.480, Sig. $=0.002$ ) were the factors significantly associated with therapists' splint prescription patterns, in addition to their perception of splint efficacy (Cramer's V 0.516 Sig. $=0.001$ ). Due to the small sample size, it was not possible to establish any logistic regression equation to define the therapists' splint prescription pattern using the therapists' perceived splinting efficacy as the key variable while statistically controlling some/all of the other contributing variables, particularly the therapists' characteristics.

\section{Discussion}

This study examined the perceived hand splinting efficacy and splint prescription pattern after stroke among inpatient OTs in Ireland. It was found that a substantial proportion of therapists perceive hand splints to be effective and continue to prescribe splints regularly to their clients despite its inadequate evidence. A similar splint prescription practice has been documented in stroke literature ${ }^{[8]}$ and also in other hand dysfunction related literature such as arthritis ${ }^{[26]}$ and tetraplegia. ${ }^{[29]}$ This positive perception and continued practice in stroke rehabilitation does not truly reflect the current evidence, which neither supports nor refutes the usefulness of splinting practice following stroke. ${ }^{[6]}$ Limited reported splinting complications coupled with inadequate evidence for its ineffectiveness might have encouraged the therapists to give the benefit of doubt in favor of prescribing splints. However such an affirmation needs scientific corroboration, particularly when healthcare costs are taken into account. Interestingly, a small number of people who reported that they do not use splints in stroke rehabilitation have identified the lack of evidence for such an intervention to be a reason for their nonprescription. This contradicting practice among therapists clearly depicts the controversy prevailing around the splinting practice.

The availability of a variety of hand splints along with a range of clinical rationales for splinting does not make it easy for both therapists and researchers to evaluate the efficacy of splinting in stroke, which makes an objective and quantitaive clinical evaluation almost impossible. However, the participants have demonstrated a strong preference for volar forearm-based wrist-hand splints - functional position splint, and a lesser preference for the wrist and finger extension splints. These splint types were also found to be significantly associated with the therapists' perception of splinting efficacy. This perception and practice of splinting is also being reflected in the literature as the majority of articles focus on the efficacy of volar forearm-based wrist-hand splints - functional position ${ }^{[5,10,15,16]}$ and/or resting position splints..$^{[13,15,30]}$ As evident in the literature, this study also found therapists addressing 'volar forearm-based wristhand splints' with different names (functional position splints and resting position splints). These difference in terminologies make communication regarding splinting and its effectiveness in stroke rather difficult and therefore, necessitating appropriate use of more universally accepted splinting terminologies both in clinical settings and in research literature.

All of the participants also preferred to use volar splints either alone or in combination with dorsal-hand splints but not dorsal-hand splints exclusively. Although the use of volar splinting is in direct conflict with some of the stroke rehabilitation theorists' views ${ }^{[7,17]}$ (theorists believe palmar stimulation by any means, including splinting, may be likely to cause an increase in UL flexor spasticity), the common practice of volar splinting suggests that more work needs to be done to gain a deeper understanding of musculoskeletal recovery following stroke. This must include the controversies surrounding palmar stimulation and their relationship with UL spasticity from a physiological perspective. Reported preferences for volar splinting by the participants were predominantly for the ease of in fabrication and for patient comfort as opposed to their clinical outcome. This finding indirectly, yet clearly describes the therapists' interests in enhancing patients' adherence to prescribed splinting protocol and the role of patients' comfort in determining adherence. Although, it is beyond the scope of this research in estimating the various factors associated with splinting adherence, this finding certainly supports the need for more research in this area, which is currently limited. It is also evident from the study that any form of dynamic 
splinting to rehabilitate the affected hand after stroke is very much under-utilized. Dynamic splinting is often one of the preferred forms of treatment techniques to improve ROM and/or to reduce soft tissue contractures secondary to neurological/orthopaedic/musculoskeletal dysfunctions. ${ }^{[31-33]}$ This may probably be associated with usability related issues due to the complex nature of such splints in UL. This needs to be researched in future studies.

Of the number of clinical rationales described, reducing hand spasticity, reducing existing soft tissue contractures and increasing joint ROM were significantly associated with the therapists' perceived splinting efficacy. These are generally the primary aims in the majority of scientific research intended for evaluating the efficacy of hand splinting following stroke. Interestingly, in the literature, findings particularly for these three aims have shown conflicting and inconclusive evidence on efficacy. ${ }^{[5,9-12,14-}$ ${ }^{15,23]}$ On the other hand, some of the secondary aims like enhancing functional independence and reducing pain that have presented some positive findings in the literature ${ }^{[10,14,15]}$ were not significantly associated with the therapists' perception of splint efficacy. This therapists' focus on reducing impairments and not improving the clients' much valued functional independence questions the clientcentered practice of OTs. When the evidence for splinting efficacy is inadequate such an imposition of splints into the life of these clients may potentially lead to unnecessary burden both to the clients and their carers. However, a common limitation of not obtaining in-depth information in a quantitative survey methodology demands appropriate future research to corroborate such an assertion.

It was evident that a majority of the therapists trusted their clinical experience and depended on clinical observation in estimating splint efficacy for various clinical rationales. Due to the limited availability of wellestablished objective assessment tools in rehabilitation, relying on subjective assessments is a common practice among stroke therapists. ${ }^{[34]}$ However, the prevalence of subjectivity in clinical practice coupled with inadequate scientific evidence often confuses therapists and weakens their fundamental belief in treatment efficacy. ${ }^{[19]}$ Therefore, it is vital to establish a culture of objectivity among therapists in current splinting practice. Thus to establish clinical objectivity and to ensure effective evidence based practice, development of appropriate, therapeutically meaningful, objective and sensitive assessment methods that are easy to administer in a routine clinical setting is fundamental.

Irrespective of educational qualifications, the influence of occupational therapy training (both at undergraduate and postgraduate level) was found to be the only therapist-related factor that the group associated with their positive perception of splinting efficacy. However, due to the limited information gathered in this research regarding therapists' education and the limitations posed by the research design (cross-sectional survey), the researchers were not able to establish any causal relationships between the therapists' current knowledge and their education about splinting. Yet this study clearly reflects the importance of education in practice and the need for specific continued education for adequate specialized knowledge and healthy clinical practice. This finding of university education as another factor associated with therapists' perception of splint efficacy indicates the importance of occupational therapy educators' role in shaping the therapists' clinical practice. Therefore, evaluating educators' perspective on hand splinting in stroke through research in the future may provide more useful information in this regard.

It is also evident from the study that the therapists' perception of efficacy is one of the major factors associated with therapists' splint prescription patterns following stroke. Therefore, the need to educate therapists about current evidence and an appropriate transfer of research knowledge to influence their perception and practice of splinting following stroke is warranted. However, this needs to be done cautiously and only after carefully studying the effectiveness of splinting in various domains, particularly in the areas where the therapists perceive hand splints to be most effective. Unfortunately, the current inadequate understanding of splinting efficacy due to lack of high quality studies in this area makes it difficult to develop a scientifically informed knowledge-base for an adequate and appropriate education at present. Therefore, developing scientific evidence in proving the efficacy of hand splints following stroke is both fundamental and crucial.

Adhering to available splinting guidelines was another factor that was significantly associated with the therapists' splint prescription pattern. Currently available clinical guidelines, however, are neither specific nor comprehensive and therefore far from complete. ${ }^{[35-38]}$ This has forced the therapists to develop and depend on individualized, hospital-specific guidelines, also evident in the study. These guidelines are likely to differ significantly between therapists and/or hospitals because of their nature, thus making it difficult to establish uniformity in stroke care even on a regional or national scale in a country as small as Ireland. However, on a positive note the therapists' preference for following guidelines would make it relatively easy to deliver an acceptable level of care when an appropriate and 
comprehensive splinting guideline is developed based on the scientific evidence for splinting in stroke.

The lack of established splinting guidelines seems to be playing a role not only in making decisions about splint prescription but also in establishing a wearing regimen. Even though most of the therapists concur in their belief of splinting being effective there is no consensus among them about how and when to prescribe splints. There is confusion among therapists particularly in establishing splinting protocol since some prefer night-splinting, some day-splinting and others prefer a combination of both. There is also no consensus regarding the optimal amount of time that a client should wear a splint. This lack of concensus is also evident in the literature. A wearing regimen in splint therapy could be somewhat equated with dosage in drug therapy. Therefore, it is vital to establish splint-wearing regimens based on similar scientific rigor. The lack of scientific literature focusing on this element of splinting rehabilitation makes structured splinting therapy a difficulty for the therapists. This eventually results in developing an individualistic protocol based on personal experience and not on evidence, which may prove to be quite detrimental to the health and wellbeing of some stroke patients if not dealt with appropriately. Thus this study identifies a varied splinting practice among inpatient OTs in Ireland, emphasising the need for establishing uniformity of care in stroke rehabilitation, also necessitating a similar study including more participants across the globe in future.

\section{Acknowledgements}

Authors would like to thank all the study participants for their time. We would like to thank Dr. Glavin, Ms. O'Malley, Dr. Armstrong, Ms. Berthuad and Ms. Rajasekaran for their review and invaluable comments on the manuscript. Special thanks to Mr. Sriram and Ms. Breen for their constructive comments in the development of the survey questionnaire and to Mr. Cornelius for the splint pictures.

\section{References}

1. Farrell JF, Hoffman HB, Snyder JL, Giuliani CA, Bohannon RW. Orthotic aided training of the paretic upper limb in chronic stroke: Results of a phase 1 trial. NeuroRehabilitation 2007;22:99-103.

2. National Audit of Stroke Care by the Irish Heart Foundation National Audit Council of Stroke Care (2008) in association with the Department of Health and Children. Available from: http://www.irishheart.ie/open24/ pub/strokereports/stroke_report.pdf. [Last acceseed on 2011 Jan 05].

3. Pandyan AD, Cameron M, Powell J, Stott DJ, Granat MH. Contractures in the post-stroke wrist: A pilot study of its time course of development and its association with upper limb recovery. Clin Rehabil 2003;17:88-95.

4. Wilton JC. Splinting and casting in the presence of a neurological dysfunction. In: Wilton JC, editor. Hand splinting: Principles of design and fabrication. London: WB Saunders; 1997. p. 168-97.

5. Lannin NA, Horsley SA, Herbert R, McCluskey A, Cusick A. Splinting the hand in the functional position after brain impairment: A randomized, controlled trial. Arch Phys Med Rehabil 2003;84:297-302.

6. Lannin NA, Herbert RD. Is hand splinting effective for adults following stroke? A systematic review and methodologic critique of published research. Clin Rehabil 2003;17:807-16.

7. Milazzo S, Gillen G. Splinting Applications. In: Gillen G, Burkhardt A, editors. Stroke rehabilitation: A function-based approach. 2nd ed. Mosby: Elsevier Incorporated; 2004.

8. Neuhaus BE, Ascher ER, Coullon BA, Donohue MV, Einbond A, Glover JM, et al. A survey of rationales for and against hand splinting in hemiplegia. Am J Occup Ther 1981;35:83-90.

9. Langlois S, Pederson L, Mackinnon JR. The effects of splinting on the spastic hemiplegic hand: Report of a feasibility study. Canadian J Occup Ther 1991;58:17-25.

10. Pizzi A, Carlucci G, Falsini C, Verdesca S, Grippo A. Application of a volar static splint in poststroke spasticity of the upper limb. Arch Phys Med Rehabil 2005;86:1855-9.

11. Steultjens EM, Dekker J, Bouter LM, van de Nes JC, Cup EH, van den Ende CH. Occupational therapy for stroke patients: A systematic review. Stroke 2003;34:676-87.

12. Watson MJ, Crosby P, Matthews M. An evaluation of the effects of a dynamic lycra orthosis on arm function in a late stage patient with acquired brain injury. Brain Inj 2007;21:753-61.

13. Gracies JM, Marosszeky JE, Renton R, Sandanam J, Gandevia SC, Burke D. Short-term effects of dynamic lycra splints on upper limb in hemiplegic patients. Arch Phys Med Rehabil 2000;81:1547-55.

14. Rose V, Shah S. A comparative study on the immediate effects of hand orthoses on reduction of hypertonus. Aust Occup Ther J 1980;34:59-64.

15. Lannin NA, Cusick A, McCluskey A, Herbert RD. Effects of splinting on wrist contracture after stroke: A randomized controlled trial. Stroke 2007;38:111-6.

16. Harvey L, de Jong I, Goehl G, Mardwedel S. Twelve weeks of nightly stretch does not reduce thumb web-space contractures in people with a neurological condition: A randomised controlled trial. Aust J Physiother 2006;52:251-8.

17. Shah S. Wrist splint for upper motor neuron paralysis. Stroke 2007;38:e74.

18. Manigandan C, Charles J. Effect of hand splinting: Isn't temporality crucial? Stroke 2007;38:e146.

19. Davies HT, Nutley SM. The rise and rise of evidence in health care. Public Money Manag 1999;19:9-16.

20. Turk R, Burridge JH, Davis R, Cosendai G, Sparrow O, Roberts HC, et al. Therapeutic effectiveness of electric stimulation of the upper-limb poststroke using implanted microstimulators. Arch Phys Med Rehabil 2008;89:1913-22.

21. Masiero S, Celia A, Rosati G, Armani M. Robotic-assisted rehabilitation of the upper limb after acute stroke. Arch Phys Med Rehabil 2007;88:142-9.

22. Barreca S, Wolf SL, Fasoli S, Bohannon R. Treatment interventions for the paretic upper limb of stroke survivors: A critical review. Neurorehabil Neural Repair 2003;17:220-6.

23. Sirtori V, Corbetta D, Moja L, Gatti R. Constraint-induced movement therapy for upper extremities in stroke patients. Cochrane Database Syst Rev 2009;4:CD004433.

24. Woldag H, Hummelsheim H. Evidence-based physiotherapeutic concepts for improving arm and hand function in stroke patients: A review. J Neurol 2002;249:518-28.

25. Hara Y. Neurorehabilitation with new functional electrical stimulation for hemiparetic upper extremity in stroke patients. J Nippon Med Sch 2008;75:4-14.

26. Thomas G. How to do your Research project: A guide for students in education and applied social sciences. London: SAGE Publications Limited; 2009.

27. Davenport BJ. An investigation into therapists' management of osteoarthritis of the carpometacarpal joint of the thumb in the UK. Hand Therapy 2009;14:2-9.

28. Ballinger C, Davey C. Designing a questionnaire: An overview. Brit J Occup Ther 1998;61:547-50.

29. Krajnik SR, Bridle MJ. Hand splinting in quadriplegia: Current practice. Am J Occup Ther 1992;46:149-56. 


\section{Adrienne and Chockalingam: Stroke occupational therapists' hand splinting practice}

30. Sheehan JL, Winzeler-Merçay U, Mudie MH. A randomized controlled pilot study to obtain the best estimate of the size of the effect of a thermoplastic resting splint on spasticity in the stroke-affected wrist and fingers. Clin Rehabil 2006;20:1032-7.

31. Gaspar PD, Willis FB. Adhesive capsulitis and dynamic splinting: A controlled, cohort study. BMC Musculoskelet Disord 2009;10:111.

32. Lopez AL, Kalish SR, John MM, Willis FB. Reduction of ankle equinus contracture secondary to diabetes mellitus with dynamic splinting. Foot Ankle Online J 2010;3:2.

33. Farmer SE, James M. Contractures in orthopaedic and neurological conditions: A review of causes and treatment. Disabil Rehabil 2001;23:549-58

34. DeLisa JA, Gans BM, Walsh NE. Physical medicine and rehabilitation; principles and practice. 4th ed. Philadelphia: Lippincott: Williams and Wilkins; 2005.

35. Irish Heart Foundation - Council for stroke. National Clinical Guidelines and recommendations for the care of people with stroke and transient Ischaemic Attack (2009). Available from: http://www.irishheart.ie/iopen24/ pub/strokereports/strokeguidelines.pdf. [Last accessed on 2011 Jan 05].

36. Intercollegiate Stroke Working Party. National clinical guideline for stroke. $3^{\text {rd }}$ ed. London: Royal College of Physicians; 2008.

37. National Stroke Foundation. Clinical Guidelines for Stroke Rehabilitation and Recovery (2005). Available from: http://www.nhmrc.gov.au/ publications. [Last accessed on 2011 Jan 05].

38. Duncan PW, Zorowitz R, Bates B, Choi JY, Glasberg JJ, Graham GD, et al. Management of Adult Stroke Rehabilitation Care: A clinical practice guideline. Stroke 2005;36:e100-43.

How to cite this article: Adrienne C, Manigandan C. Inpatient occupational therapists hand-splinting practice for clients with stroke: A cross-sectional survey from Ireland. J Neurosci Rural Pract 2011;2:141-9.

Source of Support: Nil. Conflict of Interest: None declared.

\section{Dispatch and return notification by E-mail}

The journal now sends email notification to its members on dispatch of a print issue. The notification is sent to those members who have provided their email address to the association/journal office. The email alerts you about an outdated address and return of issue due to incomplete/incorrect address.

If you wish to receive such email notification, please send your email along with the membership number and full mailing address to the editorial office by email. 